\title{
Dexmedetomidine does not produce vasocontraction on human isolated gastroepiploic artery
}

\author{
Won-Sung Kim ${ }^{1,2}$, Seung-Hoon Baek ${ }^{1,2}$, Sang Kwon Lee ${ }^{2,3}$, Tae Yong Jeon ${ }^{2,4}$, Hee-Young Kim ${ }^{1,2}$, and \\ Sang Wook Shin ${ }^{1,2}$ \\ ${ }^{1}$ Department of Anesthesia and Pain Medicine, Pusan National University School of Medicine, ${ }^{2}$ Medical Research Institute, Pusan \\ National University Hospital, Departments of ${ }^{3}$ Thoracic and Cardiovascular Surgery, ${ }^{4}$ General Surgery, Pusan National University \\ School of Medicine, Yangsan, Korea
}

Background: Recently, the addition of dexmedetomidine to sedation regimens after cardiac surgery had been reported and there is a possibility that dexmedetomidine can cause vasoconstriction. Vasopressin has been used as a prophylactic treatment for refractory vasodilatory shock during coronary artery bypass graft (CABG). Also, vasopressin may play an important role in initiating spasms at the graft artery. Here we evaluate the direct effect of dexmedetomidine on isolated human gastroepiploic arteries and the synergistic effect of dexmedetomidine and vasopressin.

Methods: Discarded gastroepiploic arteries from elective subtotal gastrectomy $(\mathrm{n}=10)$ were used in this study. We measured the level of contraction in isolated human gastroepiploic arteries induced by increasing concentrations of dexmedetomidine $\left(10^{-10}\right.$ to $\left.10^{-6} \mathrm{M}\right)$ with or without vasopressin $\left(10^{-10}, 10^{-9} \mathrm{M}\right)$. Arterial contractions caused by increasing concentrations of vasopressin $\left(10^{-10}\right.$ to $\left.10^{-7.5} \mathrm{M}\right)$ with or without dexmedetomidine $\left(10^{-9}, 10^{-7} \mathrm{M}\right)$ were also measured in the tissue samples.

Results: Supraclinical concentrations of dexmedetomidine elicited contractions at concentrations of $10^{-7} \mathrm{M}$ and $10^{-6} \mathrm{M}(\mathrm{P}<0.05$ versus resting tension $)$. The same concentrations of dexmedetomidine $\left(10^{-7}, 10^{-6} \mathrm{M}\right)$ significantly enhanced vasopressin-induced contractions ( $\mathrm{P}<0.05$ versus vasopressin-induced contraction). Vasopressin produced concentration-dependent contractions and vasopressin $\left(10^{-10}, 10^{-9.5}, 10^{-9} \mathrm{M}\right)$ also increased the intensity of dexmedetomidine $\left(10^{-7} \mathrm{M}\right)$ induced contractions.

Conclusions: There was a synergistic effect between supraclinical doses of dexmedetomidine and vasopressin on the degree of contraction in isolated human gastroepiploic arteries. However, a sedative dose of dexmedetomidine (clinical dose: $0.2-0.7 \mu \mathrm{g} / \mathrm{kg} / \mathrm{hr}$, plasma concentration: $0.36-1.25 \mathrm{ng} / \mathrm{ml}$ ) did not enhance vasopressin inducedcontraction in isolated human gastroepiploic arteries. (Korean J Anesthesiol 2011; 60: 428-433)

Key Words: Coronary artery bypass surgery, Dexmedetomidine, Gastroepiploic artery, Vasopressin.

Received: October 14, 2010. Revised: December 13, 2010. Accepted: December 15, 2010.

Corresponding author: Seung-Hoon Baek, M.D., Ph.D., Department of Anesthesia and Pain Medicine, Pusan National University Yangsan Hospital, Beomeo-ri, Mulgeum-eup, Yangsan 626-770, Korea. Tel: 82-55-360-1019, Fax: 82-55-360-2149, E-mail: md.baeksh@gmail.com This work was supported by Pusan National University Research Grant, 2010.

(c) This is an open-access article distributed under the terms of the Creative Commons Attribution Non-Commercial License (http:// creativecommons.org/licenses/by-nc/3.0/), which permits unrestricted non-commercial use, distribution, and reproduction in any medium, provided the original work is properly cited. 


\section{Introduction}

Persistent hypotension associated with low systemic vascular resistance and high cardiac output has been termed "vasoplegic syndrome" [1]. Treatment for vasoplegic syndrome involves inotropic support and the administration of high doses of vasopressors. Recent studies have reported that intravenous administration of vasopressin was beneficial in patients with persistent hypotension associated with sepsis or from cardiac surgeries involving cardiopulmonary bypass (CPB) [24]. Vasopressin is important in the maintenance of vascular tone after $\mathrm{CPB}$, as a deficiency in vasopressin contributes to vasoplegic syndrome. Both high dose ( 0.1 to $1 \mathrm{IU} / \mathrm{min})$ and low dose $(0.03 \mathrm{IU} / \mathrm{min})$ vasopressin are effective in the treatment of vasoplegic syndrome after cardiac surgeries involving CPB $[3,4]$. However, vasopressin can be a strong vasoconstrictor in the internal thoracic and radial arteries [5], and these vessels are often used for coronary artery bypass grafting (CABG) [6].

The use of dexmedetomidine (DMT) is associated with a reduction in the dosage of anesthetics and analgesic drugs used during the perioperative period, and it is also used in clinical practice for sedation in the ICU after cardiac operations. Activation of presynaptic $\alpha_{2}$-adrenoceptors on sympathetic nerves can lead to sympatholysis in the central nervous system. However, activation of vascular postsynaptic receptors causes both vasoconstriction (through activation of the $\alpha_{2}$ adrenoceptors on the vascular smooth muscle cells) and vasodilatation (through the activation of $\alpha_{2}$-adrenoceptors on the endothelial cells). Recently, it has been reported that systemically administered DMT caused vasoconstriction with doses lower than the clinically recommended dose [7].

Since vasopressin is one of the principal vasoconstrictors for human vessels and the mechanisms of its vasoconstrictive effect are likely different than the mechanisms for DMT-induced vasoconstriction, there is a possibility of a synergic effect with vasopressin and DMT in human arteries. Despite extensive use of both drugs to induce vasoconstriction, there is scant information available in their postoperative management for CABG. In this study, we hypothesized that DMT can enhance vasopressin-induced contraction in human gastroepiploic arteries (GEA). Moreover, we evaluated the effect of vasopressin on DMT-induced contraction in human GEA.

\section{Materials and Methods}

This study was approved by the Institutional Review Board of the University Hospital. After informed consent was obtained, discarded GEAs were obtained from patients who underwent subtotal gastrectomy $(\mathrm{n}=10,43-74 \mathrm{yr})$. GEA segments were collected and immediately delivered to the laboratory. The tissues were then placed in an oxygenated physiologic salt solution (PSS) that was maintained at $4^{\circ} \mathrm{C}$. Fat and connective tissues were carefully removed, and vascular rings $(2-3 \mathrm{~mm}$ length) were prepared. The rings were then suspended on wires in organ baths filled with PSS. Four segments in separate organ baths with PSS were run in parallel. The PSS had the following composition (mM/L): $\mathrm{Na}^{+}, 137.4 ; \mathrm{HCO}^{3-}, 15.5 ; \mathrm{K}^{+}, 5.9 ; \mathrm{Ca}^{2+}, 2.6$; $\mathrm{H}_{2} \mathrm{PO}^{4-}, 1.2 ; \mathrm{Mg}^{2+}, 1.2 ; \mathrm{Cl}^{-}, 134.4$; and glucose, 11.5. All solutions were continuously aerated with a mixture of $95 \%$ oxygen and $5 \%$ carbon dioxide, the $\mathrm{pH}$ was adjusted to $7.3-7.4$ and the temperature was kept at $37^{\circ} \mathrm{C}$.

Two stainless steel hooks were introduced through the lumen of the vascular ring. One hook was anchored to the bottom of the organ bath, and the other was connected to a strain gauge to measure the level of isometric force. The vascular rings were stretched gradually to a resting tension of $2 \mathrm{~g}$ during a 90-120 min equilibration period to obtain optimal tension. After the equilibration period, $60 \mathrm{mM}$ of $\mathrm{KCl}$ was added to the baths and the contractile force was recorded. For each vessel segment, the greatest contraction elicited by $\mathrm{KCl}$ was used as a reference point for the remaining contractions and test contractions were expressed as a percentage of the reference contraction. The vascular rings were then washed (at least 2 times) with PSS to restore the basal contraction levels (i.e. vascular rings had a second equilibration period).

The following drugs were used: DMT (Orion Pharma, Turku, Finland) and arginine vasopressin (Sigma-Aldrich Korea, Youngin, Kyunggi, Korea).

\section{Experiment 1}

To establish a dose-response curve, increasing doses of $\operatorname{DMT}\left(10^{-10}, 10^{-9}, 10^{-8}, 10^{-7}\right.$ and $\left.10^{-6} \mathrm{M}\right)$ were added in a cumulative fashion to the organ baths at $3 \mathrm{~min}$ intervals to allow the vascular rings to respond to each concentration, and the contractile force was subsequently assessed after each addition.

Then, vasopressin $\left(10^{-10}\right.$ or $\left.10^{-9} \mathrm{M}\right)$ was also added to the organ baths. After $5 \mathrm{~min}$, DMT was added cumulatively in increasing doses $\left(10^{-10}, 10^{-9}, 10^{-8}, 10^{-7}\right.$ and $\left.10^{-6} \mathrm{M}\right)$ to the organ baths at $3 \mathrm{~min}$ intervals and the contractile force was assessed as above.

\section{Experiment 2}

To establish a dose response for vasopressin $\left(10^{-10}, 10^{-9.5}\right.$, $10^{-9}, 10^{-8.5}, 10^{-8}$, and $10^{-7.5} \mathrm{M}$ ), it was added cumulatively to the organ baths at $3 \mathrm{~min}$ intervals and the contractile response was assessed after each addition.

Next, DMT $\left(10^{-9}\right.$ or $\left.10^{-7} \mathrm{M}\right)$ was added to the organ baths. After $5 \mathrm{~min}$, increasing concentrations of vasopressin were then 
added cumulatively $\left(10^{-10}, 10^{-9.5}, 10^{-9}, 10^{-8.5}, 10^{-8}\right.$, and $\left.10^{-7.5} \mathrm{M}\right)$ to the organ baths at $3 \mathrm{~min}$ intervals, and the contraction force was assessed after each addition.

Contractile responses were expressed as percentages of the maximum contraction in isotonic $60 \mathrm{mM} \mathrm{KCl}$. When similar experiments were performed on more than one segment from the same patient, a mean for each patient was calculated before statistical analysis.

Results were expressed as the mean \pm SD. The data were analyzed by analysis of variance (ANOVA), followed by a Scheffe post-hoc test to detect individual differences and by an

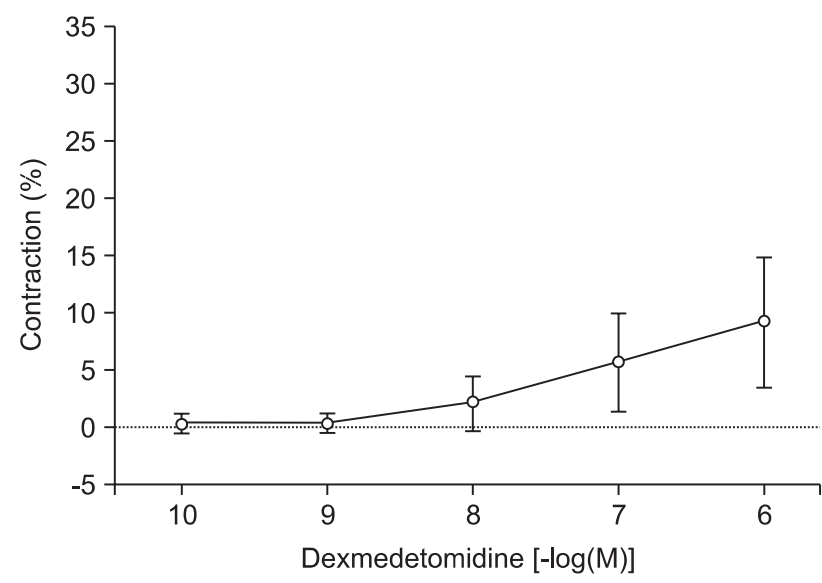

Fig. 1. Effects of increasing concentrations of dexmedetomidine on human gastroepiploic arterial contraction. Data are expressed as percent (\%) contraction of dexmedetomidine to a contraction induced from addition of $60 \mathrm{mM} \mathrm{KCl}$.

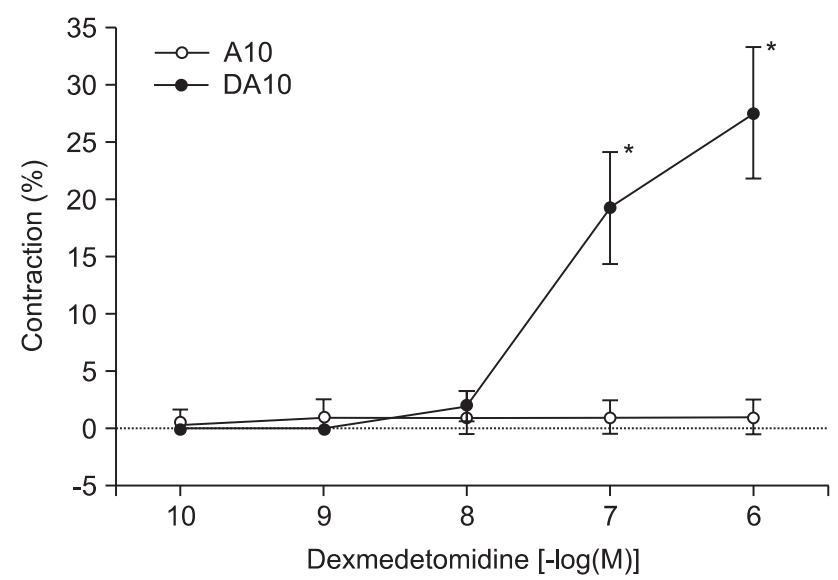

Fig. 2. Dexmedetomidine induced contraction of human gastroepiploic artery with and without vasopressin $\left(10^{-10} \mathrm{M}\right)$. Data are expressed as percent (\%) contraction of dexmedetomidine to a contraction induced from addition of $60 \mathrm{mM} \mathrm{KCl}$. A10: contraction from $10^{-10} \mathrm{M}$ of arginine vasopressin treatment, DA10: contraction from increasing doses of dexmedetomidine after vasopressin $\left(10^{-10} \mathrm{M}\right)$ treatment, $* \mathrm{P}<0.05$ when compared with that of $10^{-10} \mathrm{M}$ of arginine vasopressin treatment. unpaired t test to compare two independent groups. Differences were considered significant when $\mathrm{P}<0.05$.

\section{Results}

When DMT $\left(10^{-10}, 10^{-9}, 10^{-8}, 10^{-7}\right.$ and $\left.10^{-6} \mathrm{M}\right)$ was added cumulatively to the organ bath, the drug induced significant contractions at the higher concentrations $\left(10^{-7} \mathrm{M}: 5.6 \pm 4.2 \%\right.$, $10^{-6} \mathrm{M}: 9.3 \pm 5.7 \%$ of the maximal contraction produced by $60 \mathrm{mM}$ of $\mathrm{KCl}$; $\mathrm{P}<0.05$ versus resting tension, Fig. 1). High concentrations of DMT significantly enhanced contractions induced by $10^{-10} \mathrm{M}$ of vasopressin $\left(10^{-7} \mathrm{M}\right.$ : $19.3 \pm 4.9 \%, 10^{-6} \mathrm{M}$ : $27.6 \pm 5.8 \%$ of the maximum contraction produced by $60 \mathrm{mM}$ of KCl; $\mathrm{P}<0.05$ versus $10^{-10} \mathrm{M}$ vasopressin-induced contraction, Fig. 2).

High concentrations of DMT similarly enhanced the contractions induced by $10^{-9} \mathrm{M}$ of vasopressin $\left(10^{-7} \mathrm{M}: 80.2\right.$ $\pm 9.7 \%, 10^{-6} \mathrm{M}: 86.6 \pm 11.2 \%$ of the maximum contraction produced by $60 \mathrm{mM}$ of $\mathrm{KCl}$; $\mathrm{P}<0.05$ versus $10^{-9} \mathrm{M}$ vasopressininduced contraction, Fig. 3$)$. When vasopressin $\left(10^{-10}\right.$ to $10^{-7.5}$ $\mathrm{M}$ ) was added cumulatively to the vessel segments in the organ bath, the drug induced concentration-dependent contractions (Fig. 4)

Vasopressin did not significantly enhance contractions elicited by $10^{-9} \mathrm{M}$ concentrations of DMT (Fig. 5). However, lower concentrations of vasopressin $\left(10^{-10}, 10^{-9.5}\right.$, and $\left.10^{-9} \mathrm{M}\right)$ did significantly enhance contractions induced by $10^{-7} \mathrm{M}$ DMT $\left(10^{-10} \mathrm{M}: 19.4 \pm 3.8 \%, 10^{-9.5} \mathrm{M}: 23.4 \pm 4.3 \%, 10^{-9} \mathrm{M}: 88.9 \pm 14.1 \%\right.$ of the maximum contraction produced by $60 \mathrm{mM}$ of $\mathrm{KCl}$; $\mathrm{P}<0.05$

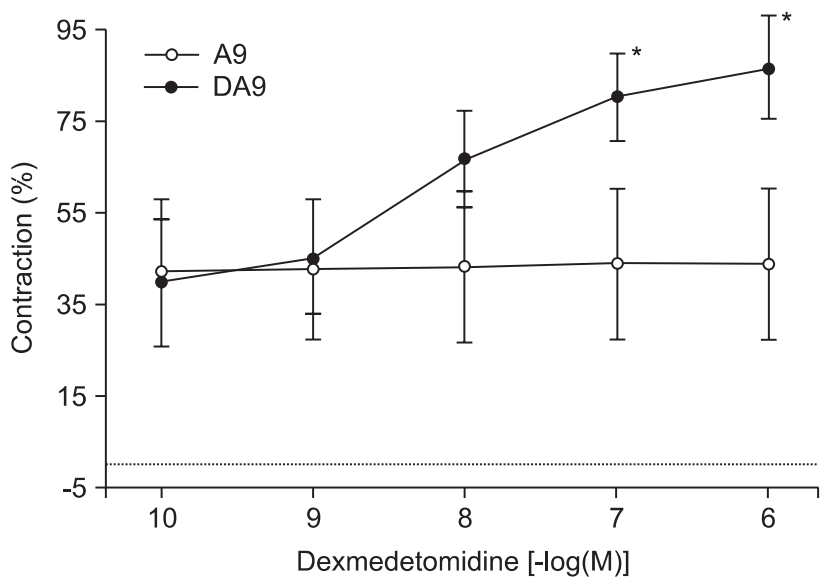

Fig. 3. Dexmedetomidine-induced contractions in human gastroepiploic arteries with and without vasopressin $\left(10^{-9} \mathrm{M}\right)$. Data are expressed as percent (\%) contraction of dexmedetomidine to a contraction induced from addition of $60 \mathrm{mM} \mathrm{KCl}$. A9: contraction from $10^{-9} \mathrm{M}$ of arginine vasopressin treatment, DA9: contraction from increasing doses of dexmedetomidine after vasopressin $\left(10^{-9} \mathrm{M}\right)$ treatment, $* \mathrm{P}<0.05$ when compared with that of $10^{-9} \mathrm{M}$ of arginine vasopressin treatment. 


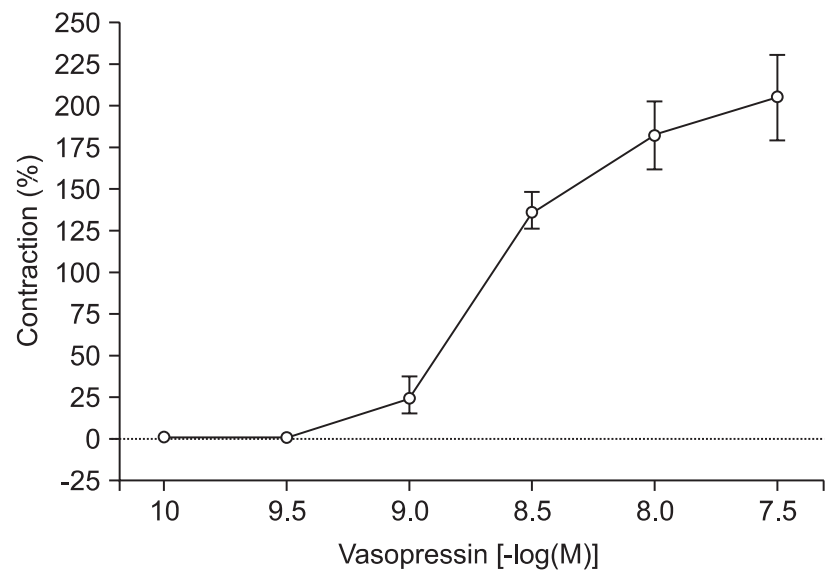

Fig. 4. Increasing concentrations of vasopressin-induced contractions in human gastroepiploic arteries. Data are expressed as percent (\%) contraction of vasopressin to a contraction induced from addition of $60 \mathrm{mM} \mathrm{KCl}$.

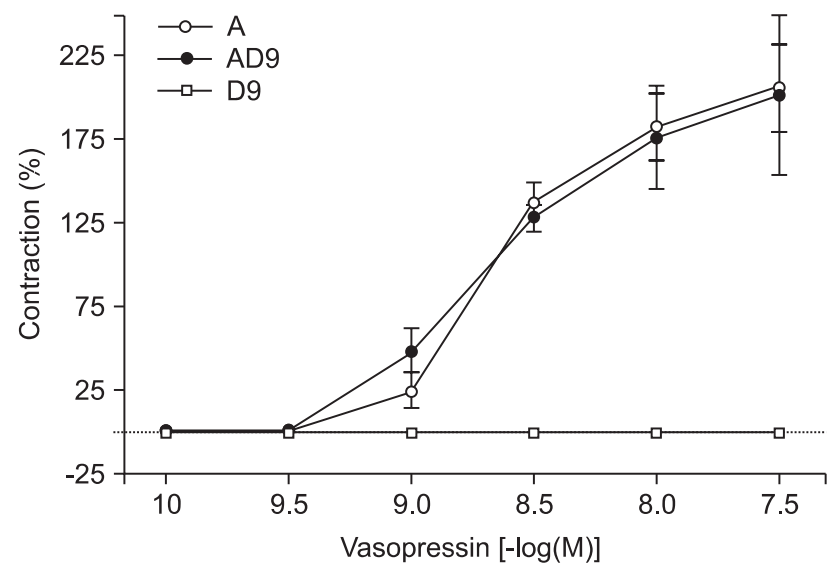

Fig. 5. Vasopressin induced contraction with and without dexmedetomidine $\left(10^{-9} \mathrm{M}\right)$ in human gastroepiploic arteries. Data are expressed as percent (\%) contraction of dexmedetomidine to a contraction induced from addition of $60 \mathrm{mM} \mathrm{KCl}$. A: contraction from arginine vasopressin treatment, AD9: contraction from increasing doses of vasopressin after dexmedetomidine $\left(10^{-9} \mathrm{M}\right)$ treatment, D9: contraction from $10^{-9} \mathrm{M}$ of dexmedetomidine treatment.

versus $10^{-7}$ M DMT-induced contraction, Fig. 6).

\section{Discussion}

In the present study, we explored the effects of DMT on vasopressin-induced contractions on human GEA. In our study, DMT alone caused significant vasoconstriction at the higher concentrations $\left(10^{-7}\right.$ and $\left.10^{-6} \mathrm{M}\right)$. When high levels of DMT were added to vessels already exposed vasopressin, there was a significant enhancement of vasopressin-induced contractions, indicating a a synergistic effect between high levels of DMT and vasopressin on vasoconstriction in human GEA.

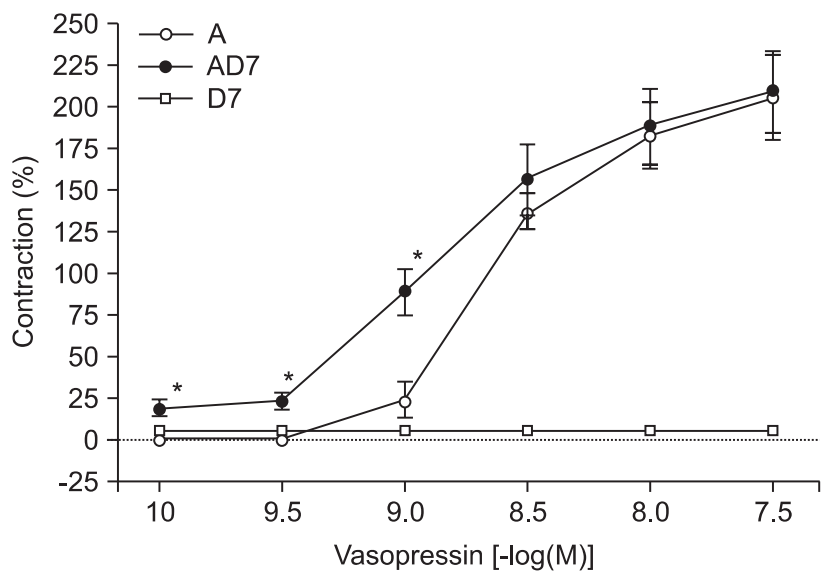

Fig. 6. Vasopressin induced contraction with and without dexmedetomidine $\left(10^{-7} \mathrm{M}\right)$ in the human gastroepiploic artery. Data are expressed as percent (\%) contraction of vasopressin to a contraction induced from addition of $60 \mathrm{mM} \mathrm{KCl}$. A: contraction from arginine vasopressin treatment, $\mathrm{AD} 7$ : contraction from increasing doses of vasopressin after dexmedetomidine $\left(10^{-7} \mathrm{M}\right)$ treatment, D7: contraction from $10^{-7} \mathrm{M}$ of dexmedetomidine treatment, $* \mathrm{P}<0.05$ when compared with that of arginine vasopressin without dexmedetomidine treatment.

DMT is the most selective $\alpha_{2}$-adrenoceptor agonist available for clinical use. Rapid injection of DMT can cause vasoconstriction and result in transient hypertension through the activation of $\alpha_{2}$-adrenoceptors on vascular smooth muscle cells $[8,9]$. The stimulation of $\alpha_{1}$-adrenoceptors by higher concentrations of DMT may also contribute to vasoconstriction $[10,11]$. This suggests that, when there is no sympathetic inhibition from the central nervous system (in other words, when there is no effects of $\alpha_{2}$-adrenoceptor agonists in the central nervous system), the peripheral vascular effect (i.e. vasoconstriction) is unmasked. Talke et al. [7] reported that systemic administration of DMT led to peripheral vasoconstriction with minimal contribution from the sympatholytic effects of the drug. Yildiz et al. [12] suggested that DMT induced concentration-dependent contractions in isolated human internal mammary arteries by activating $\alpha_{2}$-adrenoceptors at lower concentrations and $\alpha_{1}$-adrenoceptors at higher concentrations. However, only large doses of DMT $\left(10^{-7}\right.$ and $\left.10^{-6} \mathrm{M}\right)$ in vitro produced significant contractions alone in human GEA in our experiment. Our results suggest that clinical doses $\left(<10^{-7} \mathrm{M}\right.$, $0.2-0.7 \mu \mathrm{g} / \mathrm{kg} / \mathrm{hr}$ ) of DMT could not induce smooth muscle contraction in human GEA and these findings are contrary to previously published reports [12].

When DMT was added to vessels with vasopressin already present, there was a significant enhancement of vasopressininduced contraction, but only with high doses of DMT $\left(10^{-7}\right.$ and $\left.10^{-6} \mathrm{M}\right)$. Previous reports have suggested that $\alpha_{2}$-adenoreceptorinduced contractions are dependent on $\mathrm{Ca}^{2+}$ influx through 
the L-type voltage-dependent calcium channels [13]. In our experiment, DMT may have directly affected the vascular smooth muscles at higher concentrations $\left(>10^{-7} \mathrm{M}\right)$ and this is similar to previously reported results. Nielsen et al. suggested that compared to responses mediated by stimulation of postjunctional $\alpha_{1}$ - adrenoceptors, stimulation of postjunctional $\alpha_{2}$-adrenoceptors relies heavily on calcium influx. Stimulation of postjunctional $\alpha_{2}$-adrenoceptors is, however, also coupled to intracellular release of calcium in isolated human subcutaneous resistance arteries.

When vasopressin $\left(10^{-10}\right.$ to $\left.10^{-7.5} \mathrm{M}\right)$ was added cumulatively to the vessel segments in the organ bath, it produced concentration-dependent contractions. DMT at $10^{-7} \mathrm{M}$ further enhanced vasopressin-induced contractions with either physiologic or clinical doses of vasopressin $\left(10^{-10}, 10^{-9.5}, 10^{-9}\right.$ $\mathrm{M})$. However, $10^{-9} \mathrm{M}$ of DMT did not enhance vasopressininduced contractions even at supraclinical concentrations of vasopressin (>10 $\left.10^{-9} \mathrm{M}\right)$. Henderson and Byron [14] reported that vasopressin-induced contraction has two concentrationdependent signaling pathways. Protein kinase $\mathrm{C}$ activation and $\mathrm{Ca}^{2+}$ entry through the voltage-dependent L-type calcium channels are required for picomolar vasopressininduced contractions. Moreover, nanomolar concentrations of vasopressin can acutely activate the phospholipase $C$ and inositol 1,4,5-triphosphate-dependent $\mathrm{Ca}^{2+}$ release pathways. In our study, vasopressin-induced contractions at picomolar levels was enhanced by adding $10^{-7} \mathrm{M}$ of DMT. Thus, this indicated that DMT only directly affected the vascular smooth muscles at higher concentrations $\left(>10^{-7} \mathrm{M}\right)$ and that it produced a marked enhancement of the vasopressin-induced contractions through voltage-dependent L-type calcium channels. The vasoconstrictive activity of vasopressin also requires the $\mathrm{Ca}^{2+}$ signaling pathway. The mechanism of vasopressin is related to the stimulation of $\mathrm{V}_{1}$-receptors on vascular smooth muscle cells and increased intracellular $\mathrm{Ca}^{2+}$ leads to arteriolar vasoconstriction. The degree of vasoconstriction is dependent on the diameter and location of the artery. Vasopressin-induced contraction at nanomolar doses involved a different signaling pathway and the contraction effect was more potent than the effect seen with $10^{-7} \mathrm{M}$ of DMT.

Our study has several limitations. First, several reports have already shown the inhibitory effect of DMT on phenylephrineinduced contraction in GEA and in internal mammary arteries. This effect was related to the presynaptic $\alpha_{2}$-antagonist effect of DMT or the activation of $\alpha_{2}$-adrenoreceptors on endothelial cells, both of which can trigger the release of endotheliumderived nitric oxide. In our study, we used isolated human GEA and they were denervated, i.e. without a presynaptic $\alpha_{2}$ antagonist effect of DMT. The presynaptic $\alpha_{2}$-antagonist effect of DMT is important. Therefore, it is hard to directly apply our results to the clinical setting. Second, although all arterial grafts develop vasospasms, it occurs more frequently in GEA [15] and this led us to select isolated GEA for our experiments. However, there is a possibility that the results may be different in other vessels. Generally, vasospasm of the graft artery is related to the endothelial function of the graft artery. The nitric oxide and the endothelium-derived hyperpolarizing factor released from the endothelium of the graft artery may inhibit the contraction of the graft arteries. In this study with GEA, vasopressin-induced contractions overcame the effect of endothelium-derived relaxing factor. Finally, one should be careful to extrapolate the results from this study to clinical applications. There may be many factors that can cause graft vessel spasm in the clinic. These include patient and technical variables during the operation as well as the hormonal environment. Moreover, in our experiments, there was no influence from the central nervous system, as only the $\alpha_{2}$-adrenoceptor effect were present in vascular smooth muscle cells.

In conclusion, though DMT did enhance vasopressininduced contraction, it did not directly lead to contraction of isolated human GEA at clinical doses $(0.2-0.7 \mu \mathrm{g} / \mathrm{kg} / \mathrm{hr})$. At supraclinical doses $\left(>10^{-7} \mathrm{M}\right)$, DMT significantly affected the vascular smooth muscle tone and enhanced vasopressininduced contraction. However, one should be cautious to use DMT for sedation of patients who underwent CABG and to use vasopressin in patients because our study was performed with denervated GEA in isolated preparations.

\section{References}

1. Gomes WJ, Carvalho AC, Palma JH, Teles CA, Branco JN, Silas MG, et al. Vasoplegic syndrome after open heart surgery. J Cardiovasc Surg (Torino) 1998; 39: 619-23.

2. Dünser MW, Mayr AJ, Ulmer H, Ritsch N, Knotzer H, Pajk W, et al. The effects of vasopressin on systemic hemodynamics in catecholamine-resistant septic and postcardiotomy shock: a retrospective analysis. Anesth Analg 2001; 93: 7-13.

3. Masetti P, Murphy SF, Kouchoukos NT. Vasopressin therapy for vasoplegic syndrome following cardiopulmonary bypass. J Card Surg 2002; 17: 485-9.

4. Morales DL, Garrido MJ, Madigan JD, Helman DN, Faber J, Williams MR, et al. A double-blind randomized trial: prophylactic vasopressin reduces hypotension after cardiopulmonary bypass. Ann Thorac Surg 2003; 75: 926-30.

5. Wei W, Floten HS, He GW. Interaction between vasodilators and vasopressin in internal mammary artery and clinical significance. Ann Thorac Surg 2002; 73: 516-22.

6. Wei W, Yang CQ, Furnary A, He GW. Greater vasopressin-induced vasoconstriction and inferior effects of nitrovasodilators and milrinone in the radial artery than in the internal thoracic artery. J Thorac Cardiovasc Surg 2005; 129: 33-40.

7. Talke P, Lobo E, Brown R. Systemically administered alpha2- 
agonist-induced peripheral vasoconstriction in humans. Anesthesiology 2003; 99: 65-70.

8. Ebert TJ, Hall JE, Barney JA, Uhrich TD, Colinco MD. The effects of increasing plasma concentrations of dexmedetomidine in humans. Anesthesiology 2000; 93: 382-94.

9. Link RE, Desai K, Hein L, Stevens ME, Chruscinski A, Bernstein D, et al. Cardiovascular regulation in mice lacking alpha2-adrenergic receptor subtypes b and c. Science 1996; 273: 803-5.

10. Hamasaki J, Tsuneyoshi I, Katai R, Hidaka T, Boyle WA, Kanmura Y. Dual alpha(2)-adrenergic agonist and alpha(1)-adrenergic antagonist actions of dexmedetomidine on human isolated endotheliumdenuded gastroepiploic arteries. Anesth Analg 2002; 94: 1434-40.

11. Coughlan MG, Lee JG, Bosnjak ZJ, Schmeling WT, Kampine JP, Warltier DC. Direct coronary and cerebral vascular responses to dexmedetomidine. Significance of endogenous nitric oxide synthesis. Anesthesiology 1992; 77: 998-1006.

12. Yildiz O, Ulusoy HB, Seyrek M, Gul H, Yildirim V. Dexmedetomidine produces dual alpha2-adrenergic agonist and alpha1-adrenergic antagonist actions on human isolated internal mammary artery. J Cardiothorac Vasc Anesth 2007; 21: 696-700.

13. Nielsen H, Mortensen FV, Pilegaard HK, Hasenkam JM, Mulvany MJ. Calcium utilization coupled to stimulation of postjunctional alpha- 1 and alpha-2 adrenoceptors in isolated human resistance arteries. J Pharmacol Exp Ther 1992; 260: 637-43.

14. Henderson KK, Byron KL. Vasopressin-induced vasoconstriction: two concentration-dependent signaling pathways. J Appl Physiol 2007; 102: 1402-9.

15. He GW, Yang CQ. Comparison among arterial grafts and coronary artery. An attempt at functional classification. J Thorac Cardiovasc Surg 1995; 109: 707-15. 